and every 6 months from 2014 to 2017, through a standardized autoquestionnaire.

Results: 278 patients (M/F: 0.29) aged 12.7 years on average $( \pm 4.9$, range 2-21) were taken care of between 2014 and 2017 by RESRIP. Juvenile idiopathic arthritis (JIA) ( $n=142)$, connective tissue disease ( $n$ $=49$ ) and auto-inflammatory disease (AID) $(n=32)$ are the 3 main pathologies covered. Among the 278 patients, twenty-one percent of patients needed academic support when entering the network, including: $37 \%$ in the JIA group, $34 \%$ in the connective tissue group and $18 \%$ in the AID group. Educational assistance was set up for all patients with school difficulties at inclusion but also for all the patients during their follow-up.

Patient Support: 178 Individual Action Plan (IAP) were implemented by RESRIP. Twelve patients benefited from additional time for their school exams and 10 were allowed to pass the baccalaureat (French final college exam) over two years instead of a year. In thirty patients, sports education has been adapted. Forty-one MDPH files (Departmental Houses for the Disabled) were produced to enable the establishment of a school life assistant (AVS), teaching materials and/or technical aids. Finally, 8 patients received home schooling assistance through Home Learning Assistance Services (SAPAD).

Education professional support: RERSIP established partnerships with the French National Education (FNE) and the SAPAD (home tuition service for ill children). For the FNE, RESRIP provided school doctors or nurses with: 8 continuing medical training and 25 personal interviews to explain the pathologies. In addition, 5 multidisciplinary meetings, within the institutions were organized, for 5 patients with social integration difficulties and stigmatization. RESRIP actions, has allowed a significant decrease in school absenteeism between 2014 and 2017: 3.2 days per year on average at day 1 to 0.5 days per year on average $(p<0.05)$ at 42 months. Conclusion: Over time, a better understanding of the impact of chronic illness over school and education professionals, has allowed RERSIP to improve its support. The result is a notable decline in school absenteeism and in unjustified physical education exemptions. Several projects are underway: The development of a standard IAP available for doctors, the set-up of a partnership with hospital school, willing to help for the implementation of home school support courses in addition to SAPAD.

Disclosure of Interests: : Perrine Dusser: None declared, Chrystelle Hascoet: None declared, Isabelle Koné-Paut Grant/research support from: $\mathrm{SOBI}$ has supported drug product (anakinra) for the presented study, Consultant for: SOBI, Novartis, Pfizer, Abbvie, UCB, CHUGAI, ROCHE, Linda Rossi-Semerano Grant/research support from: Roche DOI: 10.1136/annrheumdis-2019-eular.7122

\section{THU0536 LONG TERM IMMUNITY IN A PAEDIATRIC COHORT OF PATIENTS WITH RHEUMATIC DISEASES FROM A TERTIARY HOSPITAL IN SPAIN}

Laura Fernández Silveira ${ }^{1}$, M.J Gimenez ${ }^{2}$, E Andreu-Alapont ${ }^{3}$, Patricia FalomirSalcedo $^{2}$, E Serrano-Poveda ${ }^{4}$, M.I. Gonzalez-Fernández², B Lopez-Montesinos ${ }^{2}$, Inmaculada Calvo ${ }^{2} .{ }^{1}$ Hospital Virgen del Rocío, Sevilla, Spain; ${ }^{2}$ Hospital la Fe, Valencia, Spain; ${ }^{3}$ Centro de salud Campanar, Valencia, Spain; ${ }^{4}$ Centro de Salud Miguel Servet, Valencia, Spain

Background: Pediatric patients with rheumatic diseases (RD) are at increased risk of infections. Vaccines have been proved to be very effective to prevent them. Nevertheless the long-term immunity after vaccination remains quite unknown in this group.

Objectives: To comapre the long term seroprotecction in pediatric patients with rheumatic diseases who recieved measles, rubella, mumps, tetanus, diphteria, hepatitis $\mathrm{B}$, hib and meningoccocus $\mathrm{C}$ vaccination acording to the routine immunization schedule in Spain, and healthy children.

Methods: We designed a cross-sectional study including consecutive pediatric patients with RD who attended the rheumatology clinic and healthy children older than 10 y.o. The administered vaccines, treatment and pathology of each patient will be recorded. Their antibodies titters against each antigen were quantified and compared to healthy children. Results: 60 patients (median age 13 y.o IQR 10.2-12-7) and 15 healthy children (mean age 11.3 y.o. IQR 11.3-12.7) were included. In the patients group $62 \%$ were female, and $35 \%$ in healthy. Diagnosis: $85 \%$ Idiopathic juvenile arthritis, $18 \%$ Lupus or juvenile dermatomiositis. $46 \%$ had received biologic treatment sometime. Seroprotection rate was (patient vs control): measles $85 \% \%$ vs $81 \% \%$, rubeola $78.8 \%$ vs $73.3 \%$, parotiditis $84.7 \%$ vs $66.7 \%$; VHB $27 . \%$ vs $10.5 \%$, diphteria $89.5 \%$ vs $81 \%$, tetanos $64.9 \%$ vs $61.1 \%$. Hib $42 \%$ vs $53 \%$, pneumococo $92.4 \%$ vs $100 \%$, meningococcus C $12 \%$ vs $11 \%$. p $>0.05$
Conclusion: No statistical differences were detected, althought the scarce number of control subjects might have infuenced this result. There is a tendence towards a lower antibody persistence anti-Hib in patients com pared to healthy children. The response to life virus vaccine and tetanus seem to be as good as in healthy chidren.

Disclosure of Interests: : Laura Fernández Silveira: None declared, M.J Gimenez: None declared, E Andreu-Alapont: None declared, Patricia Falomir-Salcedo: None declared, E Serrano-Poveda: None declared, M.I. Gonzalez-Fernández: None declared, B Lopez-Montesinos: None declared, Inmaculada Calvo Grant/research support from: received research grants from Pfizer, Roche, Novartis, Clementia, Sanofi, MSD, BMS and GSK, Consultant for: Advisory boards: Novartis, AbbVie, Speakers bureau: AbbVie, Roche, Novartis, SOBI

DOI: 10.1136/annrheumdis-2019-eular.6378

\section{THU0537 ANGIOMATOID FIBROUS HISTIOCYTOMA MIMICKING SYSTEMIC JIA VIA MUTATION-DRIVEN IL-6 PRODUCTION}

Mark Friswell ${ }^{1}$, Stephen Owens ${ }^{2}$, Gail Halliday ${ }^{3} .{ }^{1}$ Great North Children's Hospital, Paediatric Rheumatology, Newcastle upon Tyne, United Kingdom; ${ }^{2}$ Great North Children's Hospital, Paediatric Immunology, Newcastle upon Tyne, United Kingdom; ${ }^{3}$ Great North Children's Hospital, Paediatric Oncology, Newcastle upon Tyne, United Kingdom

Background: Angiomatoid Fibrous Histiocytoma mimicking Systemic JIA via mutation-driven IL-6 production: Angiomatoid Fibrous Histiocytoma $(\mathrm{AFH})$ is a rare tumour associated with mutation-driven production of Interleukin-6 (IL-6) which causes a systemic inflammatory picture similar to Systemic Juvenile Idiopathic Arthritis (sJIA).

Objectives: A previously well 6-year old girl was referred with 6 weeks of abdominal pain, nausea, weight loss, night sweats, \& lethargy.

Examination was unremarkable apart from a $2 \mathrm{~cm}$ lump in the right popliteal fossa. This had been reported on USS 2 months earlier, at an external hospital, to be a Sebaceous cyst. There was no rash, organomegaly, lymphadenopathy, or synovitis.

She had persistent recurrent fevers of $>39 \mathrm{C}$, but not in the classical quo tidian pattern of SJIA.

Methods: Bloods showed persistent $\mathrm{Hb}<70$, platelets $>600$, ESR $>100$, \& $\mathrm{CRP}>200$.

Autoantibody \& full infection screens were negative.

Urine HMMA:creatinine ratio was minimally raised at 7.2 (normal 1.8 - 5) Faecal calprotectin, upper \& lower Gl endoscopy were normal.

Bone-Marrow Aspiration was reported as being highly reactive but with no malignancy seen.

Whole-body STIR MRI was reported as normal, but repeat localised USS $\& M R I$ of the knee showed a $27 \times 18 \times 21 \mathrm{~mm}$ well circumscribed, mixed cystic/solid lesion with marked vascularity. The lesion was then biopsied, and subsequently excised

Plasma IL-6 levels were significantly elevated at $46.7 \mathrm{pg} / \mathrm{ml}$ (normal range: $0-2)$, but normalised after excision. TNF and IL1b levels were normal

Results: Initial biopsy and FISH analysis confirmed the diagnosis of AFH with an abnormal EWSR1 signal pattern and classical EWSR1-CREB1 fusion. She went on to have a full excision, and staging investigations were negative.

$\mathrm{AFH}$ is rare $(<0.3 \%$ of all soft-tissue tumours) and arises in the deep dermis/subcutis of the extremities of children \& young adults. It has been regularly described in the axilla \& popliteal fossa. It has a high $(15 \%)$ local recurrence rate but rarely metastasises.

In $>90 \%$ of cases AFH is associated with a characteristic translocation: t (2:22) (q33:q12). This forms the fusion gene EWSR1-CREB1 which in turn leads to continuous activation of CREB1. The promoter region of IL6 has a CREB1 binding site thus causing IL-6 over-production and leading to the paraneoplastic syndrome.

Conclusion: Paraneoplastic immune dysregulation is a rare, but important cause of symptoms often otherwise associated with rheumatic diseases. Careful physical examination, and liaison with oncology teams, is needed particularly before treatment with steroids or IL-6 inhibitors such as Tocilizumab are considered

Disclosure of Interests: : Mark Friswell: None declared, Stephen Owens Consultant for: paid a consultancy fee by Chimerix to act as an advisor on a study of adenovirus in transplant patients, Gail Halliday: None declared

DOI: 10.1136/annrheumdis-2019-eular.309 